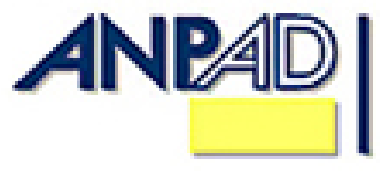

Disponível em

http://www.anpad.org.br/rac

RAC, Rio de Janeiro, v. 17, n. 4, art. 3, pp. 438-458, Jul./Ago. 2013

$(\mathrm{oc})$ EY-No

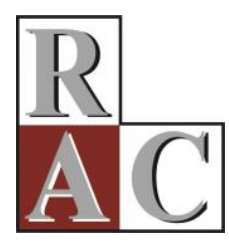

\title{
Hedge e Especulação com Derivativos Cambiais: Evidências de Operações Cotidianas
}

Hedge and Speculation with Currency Derivatives: Evidence of Everyday Operations

João Luiz Guillaumon Lopes

E-mail: joaolgl@yahoo.com.br

Banco Santander Brasil S.A.

Av. Juscelino Kubitschek, 2235, 04543-011, São Paulo, SP, Brasil.

Rafael Felipe Schiozer

E-mail: rafael.schiozer@fgv.br

Fundação Getulio Vargas - EAESP/FGV

Av. Nove de Julho, 2029, 01313-902, São Paulo, SP, Brasil.

Hsia Hua Sheng

E-mail: hsia.sheng@fgv.br

Fundação Getulio Vargas - EAESP/FGV

Av. Nove de Julho, 2029, 01313-902, São Paulo, SP, Brasil. 


\title{
Resumo
}

Este trabalho investiga a dinâmica no uso de derivativos de moedas por parte de empresas não financeiras brasileiras a partir de um banco de dados único, que contém 29 mil operações de balcão efetivamente contratadas por essas empresas junto a um grande banco internacional, entre 2003 e 2011. Embora pesquisas no Brasil (Novaes \& Oliveira, 2005; Rossi, 2011) e nos EUA (Géczy, Milton, \& Schrand, 2007) apontem para a existência de uma conduta especulativa nas decisões dos gestores, o efetivo impacto desse tipo de comportamento nas decisões da empresa ainda é pouco conhecido, bem como suas implicações para a gestão financeira de riscos e a governança corporativa. Nossa metodologia compara os retornos de contratos que foram mantidos até o vencimento, com os de contratos cuja liquidação foi antecipada pelas empresas. Os resultados mostram que, no período de 2003 a 2008, houve um forte componente especulativo nas decisões cotidianas de tomada e desmonte de posições com derivativos cambiais das empresas. Já no período de 2009 a 2011, não se identifica tal comportamento especulativo, em linha com os resultados de Coutinho, Sheng e Lora (2012). Os resultados reforçam a evidência de que as grandes perdas com derivativos cambiais em 2008 tenham funcionado como um alerta para gestores, conselheiros, investidores e reguladores, que passaram a monitorar mais atentamente as operações com derivativos.

Palavras-chave: gestão de riscos; hedge; especulação; derivativos; risco cambial.

\begin{abstract}
This study investigates the dynamics of currency derivatives usage by Brazilian non-financial firms, using a unique database of over-the-counter operations contracted between these companies and a large international bank between 2003 and 2008. Although prior studies using Brazilian (Novaes \& Oliveira, 2005; Rossi, 2011) and US (Géczy, Milton, \& Schrand, 2007) firms point to the existence of speculative behavior in managers' decisions, the effective impact of this behavior on the companies' operations is still little known, as are its implications for financial risk management and corporate governance. Our methodology compares the returns of derivatives contracts that were settled at their originally contracted maturity, with the return of contracts whose settlement was anticipated by the firm. We find evidence that routine decisions to commit to and unwind derivatives positions were influenced by speculative behavior in the period 2003-2008. However, during the period 2009-2011, we find no evidence of speculation, in line with the results of Coutinho, Sheng and Lora (2012). Our results reinforce the evidence that massive losses caused by currency derivatives in late 2008 worked as a wake-up call for managers, boards, investors and regulators, who started monitoring derivatives operations more closely.
\end{abstract}

Key words: risk management; hedge; speculation; derivatives; foreign exchange risk. 


\section{Introdução}

A teoria de Finanças mostra que a gestão de riscos com uso de derivativos pode gerar valor para a empresa na presença de imperfeições de mercado, por meio da redução dos custos de estresse financeiro, da redução da assimetria de informação, da estabilização dos fluxos de caixa para investimento e da redução da carga tributária esperada (Froot, Scharfstein, \& Stein, 1993; Smith \& Stulz, 1985; Stulz, 1984; entre outros). Diversos trabalhos se dedicam a investigar os determinantes do uso de derivativos (Allayannis \& Ofek, 2001; Bartram, Brown, \& Fehle, 2009; Géczy, Minton, \& Schrand, 1997; Nance, Smith, \& Smithson, 1993; nos EUA; Schiozer \& Saito, 2009, na América Latina - para citar alguns) e a evidência é inconclusiva acerca de quais dessas imperfeições de mercado determinam o uso destes.

No entanto, casos de grandes perdas financeiras utilizando derivativos, como Enron e Metallgesellschaft, são bem conhecidos na literatura. No Brasil, esse tema ganhou atenção no final de 2008, quando o real sofreu extrema depreciação, e empresas tradicionais, como Sadia, Aracruz e Votorantim Celulose e Papel, anunciaram perdas recordes com as operações de derivativos com suposto propósito de hedge. Embora tais casos tenham sido os mais emblemáticos, uma série de outras empresas assumiram perdas relevantes com operações similares.

As estimativas sobre as perdas das empresas brasileiras com derivativos cambiais na época variam entre USD 10 bilhões (conforme estimativa divulgada pelo então diretor de política monetária do Banco Central) e USD 25 bilhões (segundo estimativas do Bank for International Settlements [BIS]), conforme reportagem do Valor Econômico (Novos instrumentos, 2009). No final de 2008, após a divulgação desses prejuízos, a CVM (Comissão de Valores Mobiliários) emitiu a Deliberação 550, que obriga as empresas de capital aberto a divulgar trimestralmente a política de hedge adotada, o nível de exposição e de sensibilidade aos fatores de risco, e os ganhos ou perdas com derivativos.

Para entender melhor essa discussão, a recente literatura investiga diretamente a relação entre uso de derivativos e valor da firma. Os resultados ainda não são convergentes. Allayannis e Weston (2001) e Carter, Rogers e Simkins (2006) encontram evidências de que a utilização de derivativos cambiais aumenta o valor da firma, enquanto Jin e Jorion (2006), utilizando uma amostra de empresas do setor de petróleo dos EUA, encontram uma relação insignificante ou negativa.

No Brasil, essa divergência também foi encontrada. De um lado, Rossi e Laham (2008) apontam que a utilização de derivativos cambiais aumenta o valor da firma. Por outro lado, Serafini e Sheng (2011) encontraram que não há evidência de que o uso de derivativos de moedas esteja associado ao valor de mercado da firma nas empresas listadas no Brasil durante o período de 1999 a 2007. Coutinho, Sheng e Lora (2012) também demonstram que o uso de derivativos não reduzia o custo de capital das empresas até 2008. Após a crise de 2008/09, no entanto, o uso de derivativos passou a ser negativamente relacionado ao custo de capital. Esse fato pode evidenciar que os investidores não percebiam redução de risco via derivativos até 2008 (podendo indicar que os investidores já identificavam o uso especulativo de derivativos nas empresas). A partir de 2009, a redução do custo de capital pelo uso de derivativos pode indicar que os investidores passaram a enxergar o uso de derivativos como ferramenta efetiva de redução de riscos.

Nos trabalhos que se propõem a identificar se as operações com derivativos se prestam à gestão de risco ou à especulação, Novaes e Oliveira (2005) utilizaram uma base de dados do Banco Central de swaps cambiais e identificam 42 empresas de capital aberto que fizeram hedge no mercado de derivativos de câmbio e 51 que especularam. Rossi (2012) evidencia especulação com derivativos cambiais em empresas brasileiras com alegada vantagem informacional no mercado de câmbio (exportadores e empresas com dívida em moeda estrangeira).

O objetivo deste trabalho é investigar a dinâmica no uso de derivativos de moedas por parte de empresas não financeiras brasileiras. Mais especificamente, o estudo investiga se operações cotidianas com derivativos cambiais nas empresas são feitas e/ou desmontadas para especulação. Dessa forma, 
este trabalho pretende complementar os trabalhos anteriores com a utilização de uma base de dados única, com operações efetivamente contratadas pelas empresas não financeiras no mercado de balcão. Para tanto, utilizamos dados históricos com mais de 29 mil operações de derivativos cambiais contratadas por empresas de capital aberto e fechado, domésticas e estrangeiras, com a subsidiária brasileira de um grande banco internacional, no período que compreende os anos de 2003 a 2011. Isso tornou possível observar decisões efetivamente tomadas pelos gestores financeiros de maneira cotidiana, diferentemente de estudos que utilizam questionários submetidos aos gestores ou informações de notas explicativas de demonstrações financeiras, que estão limitadas às bases de dados desses demonstrativos.

Os nossos resultados mostram que, no período de 2003 a 2008, as subsidiárias brasileiras de multinacionais de capital (próprio ou da holding controladora), negociado em bolsa, são as que apresentam mais indícios de especulação. Isso pode sugerir que a existência de riscos inerentes à operação e a alegada expertise na gestão financeira (ou ainda uma alegada vantagem informacional, conforme afirma Rossi, 2012) podem ser fatores relevantes para a predisposição de uma empresa em assumir comportamento especulativo. No entanto, no período de 2009 a 2011, não se encontra evidência de especulação com derivativos cambiais. Embora não seja nosso objetivo inferir sobre as causas dessa mudança de comportamento, acreditamos que, após as grandes perdas divulgadas no final de 2008, executivos, conselheiros, investidores e reguladores tenham tornado sua atenção para a importância de monitorar mais cuidadosamente as operações com derivativos, reduzindo a possibilidade das firmas assumirem posições especulativas.

\section{Revisão Bibliográfica}

Conforme a discussão na introdução, para complementar as teorias tradicionais de hedge que justificam o uso de derivativos com base nas imperfeições de mercado, os últimos desenvolvimentos acadêmicos analisam o uso de derivativos para especulação.

Há grande quantidade de surveys e fatos anedóticos que apontam para a especulação (ou visões de mercado - market views, como a que muitos artigos se referem) quando da decisão sobre o valor e o momento para as operações com derivativos. Bodnar, Hayt e Marston (1998) revelam que 32\% das empresas que responderam a um survey sobre utilização de derivativos declaram que frequentemente ou às vezes assumem ativamente posições no mercado através de derivativos, e $60 \%$ alteram o valor e/ou o momento da operação com base em visões de mercado. Resultados semelhantes foram encontrados por Bailly, Browne, Hicks e Skerrat (2003) em survey realizado com empresas do Reino Unido: $53 \%$ e $60 \%$ das empresas alteram momento e valor do hedge, respectivamente, com base em visões de mercado, e $17 \%$ admitem tomar posições ativamente.

No Brasil, Saito e Schiozer (2007) realizaram pesquisa semelhante. Cerca de $50 \%$ dos respondentes indicaram ser avaliados por lucro ou perda absolutos, o que poderia gerar um incentivo para a especulação. No entanto, menos de $20 \%$ dos respondentes admitem assumir posições ativamente no mercado, ainda que mais de $60 \%$ alterem valor ou prazo do hedge.

Outros se debruçaram especificamente sobre a aparente contradição hedge versus especulação. Adam e Fernando (2006), analisando empresas de mineração de ouro nos EUA, propõem a existência de um prêmio pelo risco que as empresas poderiam capturar sistematicamente através do uso de derivativos, gerando fluxos de caixa esperados positivos. Allayannis e Ofek (2001) examinam se as firmas fazem hedge ou se especulam, buscando correlações entre a exposição das ações à taxa de câmbio e o uso de derivativos, entre outros fatores. Hentschel e Kothari (2001), de forma parecida, buscam identificar se as empresas estão tomando ou mitigando riscos através do uso de derivativos, analisando o retorno das ações dessas empresas. Nesse caso, não se encontrou qualquer impacto do uso de derivativos na volatilidade dos retornos das ações para as empresas analisadas. 
Brown, Crabb e Haushalter (2006) não discutem se as empresas fazem hedge ou não. Ao contrário, partem do pressuposto de que as empresas fazem hedge seletivo, conforme proposto por Stulz (1996), e buscam verificar se tal prática leva a desempenho financeiro ou operacional superiores, concluindo que tais benefícios, se existem, são irrelevantes.

Um novo ponto de vista é apresentado por Géczy, Minton e Schrand (2007). Partindo do resultado do survey de Bodnar et al. (1998), identificam os especuladores como sendo os gestores que responderam tomar ativamente posições em derivativos. Uma característica comum percebida é que os gestores que admitem tomar posições com base em visões de mercado tendem a fazê-lo em mercados relacionados à atividade operacional da empresa, o que permite supor que esses gestores acreditem ter informação superior e, possivelmente, uma vantagem para o trading nesses mercados. As firmas que especulam em moedas estrangeiras, por exemplo, têm maior percentual de suas receitas operacionais e custos denominados em moedas estrangeiras; porém, isso não explica a especulação com instrumentos de taxa de juros. A conclusão de Géczy et al. (2007) para essas características é fundamentalmente diferente das explicações fornecidas pela literatura até então, ao estabelecer hedging e trading não como atividades concorrentes, mas, sim, determinando uma relação estreita entre elas:

Taken together, these characteristics of speculators are consistent with the following scenario. Firms are motivated to use derivative instruments to hedge. Once the fixed costs of a derivatives operation are in place, however, some firms extend their derivatives program to include speculation. The firms that start speculating have (or believe they have) a comparative information advantage relative to the market such that they view speculation as a positive NPV activity (Géczy, Minton, \& Schrand, 2007, p. 2406).

Outras observações importantes são que as empresas que especulam têm baixa alavancagem, não diferem de não especuladores com relação aos incentivos para tomar risco, e não se engajam mais do que estes em outras atividades que trazem risco à empresa. Os especuladores também têm mais instrumentos internos para controle e gerenciamento de risco. Tais conclusões corroboram a ideia de que o principal motivador para a especulação seria a perspectiva da empresa de conseguir retornos positivos, ao tomar posições em mercados com maior familiaridade; e/ou de que as empresas passam a tomar posições porque têm uma vantagem de custos de transação, gerada pelo uso de derivativos para hedge. Beber e Fabri (2012) encontram que os gestores ajustam as posições em derivativos de acordo com os movimentos passados das taxas de câmbio, consistente com a ideia de visões de mercado, e que essas características são mais exacerbadas em empresas com gestores mais jovens e mais propensos a excesso de confiança.

\section{Metodologia, Descrição da Amostra e Resultados}

\section{Metodologia}

A evidenciação de operações com derivativos cambiais como sendo de hedge ou especulativas é um tanto complexa. Embora os relatórios financeiros das empresas devam fazer a distinção entre operações para proteção ou especulação, poucas empresas admitem usar derivativos para especulação. Por exemplo, a maior parte dos derivativos que causaram perdas vultosas para empresas como Aracruz e Sadia, em 2008, era classificada como hedge. Assim, diversos autores, como Beber e Fabri (2012) e Rossi (2012) usam proxies indiretas para identificar especulação. Neste trabalho, usaremos uma abordagem completamente nova, permitida pela base de dados única disponível para este estudo.

A base de dados utilizada contém os dados de todas as contratações e liquidações de operações de termo de moedas (comumente chamados no mercado de Non-Deliverable Forward [NDF]) entre a subsidiária de um grande banco estrangeiro no Brasil e seus clientes ${ }^{(1)}$, ocorridas entre janeiro de 2003 e dezembro de 2011. Oliveira, Schiozer e Leão (2012) mostram que o volume de NDF entre bancos e 
o setor não financeiro era da ordem de 60 bilhões de dólares ao final de 2011, valor superior ao dobro dos swaps cambiais (o $2^{\circ}$ tipo de contrato mais utilizado) desse mercado.

Para cada operação com derivativos, as informações disponíveis incluíam: (a) dados da operação contratada (taxa de câmbio pactuada, se era operação de compra ou venda de moeda estrangeira, e prazo da operação); (b) informações sobre a liquidação da operação (se ocorreu no vencimento inicialmente contratado, ou se a liquidação foi antecipada a pedido do cliente); e (c) um código para a empresa contratante da operação, que permite identificá-la dentro da base de dados. Por questões de sigilo bancário, não foi fornecido qualquer atributo que tornasse possível a identificação do cliente. Ou seja, é possível apreender quais operações foram contratadas por uma mesma empresa, mas não é possível perceber quem são as contratantes.

A base de operações liquidadas contém 29.485 observações, após a exclusão de operações com pessoas físicas e instituições financeiras. Dessas operações, 4.815 (16,3\%) foram liquidadas antecipadamente. Essas são operações em que o cliente (nunca o banco) solicita a liquidação antes da data de vencimento originalmente pactuada (comumente chamadas no mercado de reversões). Doravante, essas operações serão chamadas simplesmente de LA (Liquidação Antecipada), em oposição às operações que foram liquidadas na data prevista (LDP), inicialmente pactuada entre as partes.

As operações de NDF têm liquidação financeira em reais pela diferença entre o valor inicialmente contratado e o preço à vista da moeda estrangeira na data de vencimento. No caso de liquidação antecipada, ela é feita por valor acordado entre as partes, com base no valor de mercado do contrato na data. Definimos como o retorno de uma operação com NDF, o fluxo de caixa em reais (positivo ou negativo) resultante para o cliente do banco, dividido pelo valor nocional do contrato (convertido da moeda estrangeira para reais à Ptax do dia da operação).

$$
r_{i=\frac{F C_{i, T}}{\text { Nocional }_{i} \times \operatorname{Ptax}_{T}}}
$$

em que

. $\quad r_{i}$ é o retorno da operação i;

- $F C_{i, T}$ é o fluxo de caixa (positivo ou negativo) resultante para o cliente na operação $i$, na data de sua liquidação $T$ (antecipada ou não);

. Nocional $_{i}$ é o valor nocional da operação $i$, em moeda estrangeira;

- $\operatorname{Ptax}_{T}$ é o valor da Ptax do Bacen para a moeda estrangeira, na data de sua liquidação $T$.

Nossa hipótese fundamental é que, se o propósito das operações de NDF é de hedge, então a proporção de operações LDP e LA com retorno positivo não deve ser estatisticamente diferente. Para entender melhor essa argumentação, necessitamos discutir os motivos que podem justificar a decisão da empresa de liquidar o derivativo antes da data inicialmente pactuada. As possibilidades são:

1. Extinção da exposição: a obrigação ou o direito que ensejou o hedge deixou de existir ou ocorreu em data anterior à inicialmente prevista (por exemplo, o cancelamento de um contrato de exportação);

2. Mudanças no valor ou na duração das exposições financeiras: alterações podem gerar a necessidade de adequar a operação de hedge ao longo do tempo (eventualmente liquidando a operação contratada);

3. Antecipação de caixa: a empresa deseja antecipar o valor de mercado positivo de sua operação de hedge (fazer caixa com o valor positivo do contrato). Para tanto, fecha a operação original e abre uma nova, mantendo as condições (vencimento, valor) da operação original para manter a proteção cambial; 
4. Especulação por conveniência ou ex-post: posições inicialmente contratadas para hedge eventualmente atingem resultados positivos. $O$ gestor se aproveita para realizar o lucro, antecipando a liquidação do contrato, e deixando a exposição inicial desprotegida.

5. Especulação pura ou ex-ante: posições especulativas que atingem o resultado positivo esperado podem ser encerradas para realização do lucro. Alternativamente, uma operação contratada com fins puramente especulativos pode ser liquidada antecipadamente caso a perda atinja algum limite pré-estabelecido (stop loss).

Os dois primeiros motivos, que se referem a mudanças imprevistas na exposição que motivou a operação de hedge, não são correlacionados com a variação da taxa de câmbio subjacente, independentemente da posição (comprada ou vendida) e da direção do movimento da moeda estrangeira (apreciação ou depreciação). Dessa forma, partindo do pressuposto de que a operação foi inicialmente contratada para hedge, e se esses forem os motivos para a antecipação de liquidação dos contratos, a distribuição de retornos das operações LA seria similar (ou pelo menos com proporção de valores positivos similar) à observada para os contratos LDP. Assim, se a proporção de operações LA com retorno positivo for maior do que a proporção de operações LDP com retorno positivo, então pelo menos uma fração das operações foi liquidada antecipadamente por motivos diversos à extinção ou à modificação da exposição que ensejou o hedge.

O terceiro motivo, em que a empresa liquida antecipadamente a operação para fazer caixa, exige uma análise cuidadosa. Primeiramente, é necessário entender que fazer caixa não seria um objetivo da empresa no momento em que decide proteger-se de risco cambial usando instrumentos derivativos. No entanto, a companhia poderia se aproveitar de uma evolução favorável dos preços de mercado para se financiar ao receber o resultado positivo do hedge antecipadamente, enquanto o fluxo de caixa operacional que motivou o hedge ocorrerá apenas em uma data futura. Nesse caso, a liquidação antecipada é motivada pelo retorno positivo da operação (ou seja, há uma relação positiva entre a antecipação e o retorno da operação). Mas, como condição para que a empresa faça isso sem correr riscos (ou seja, sem deixar de hedgear a exposição que motivou a contratação do derivativo), seria necessário abrir uma nova posição imediatamente, mantendo valor e prazo similares aos da operação original, de forma a não se expor às variações dos preços de mercado. Essa prática é conhecida como reset da operação. Assim, caso a proporção de operações LA com resultado positivo seja maior do que a de operações LDP com resultado positivo, e não se identifique a prática de reset das operações, há pelo menos uma parcela das antecipações explicadas pelos motivos 4 ou 5 (especulação). Argumentamos que é bastante implausível a situação em que uma empresa encerre antecipadamente uma operação de NDF junto a um determinado banco e abra imediatamente uma posição com outro provedor de serviços financeiros (banco, trader ou bolsa), uma vez que o custo de transação de uma operação de reset é muito mais baixo do que uma operação com contraparte distinta da original.

É interessante notar que a especulação ex-post (motivo 4) é bastante sutil. Uma operação inicialmente contratada para reduzir a exposição cambial da empresa pode, ao assumir valor de mercado positivo, ser enxergada como uma oportunidade para realização de lucro. Nos casos em que a empresa decide realizar o lucro na operação do derivativo e não fazer o reset da operação, ela estaria assumindo o risco da exposição inicial. Caso seja essa a motivação para antecipar a liquidação do contrato, existe uma relação positiva entre liquidação antecipada e retorno da operação.

Finalmente, se uma operação tiver sido contratada com fins puramente especulativos (caso em que a empresa aposta numa direção para a taxa de câmbio), a liquidação antecipada desse contrato pode ocorrer caso o resultado objetivo tenha sido atingido, se a perda tiver atingido um valor considerado limite (stop loss), ou ainda caso o gestor mude sua visão de mercado e identifique que o retorno esperado de manter a posição aberta não compense seu risco. Assim, não é possível estabelecer uma relação entre a antecipação da operação e seu retorno (positivo ou negativo). A Tabela 1 resume os motivos para antecipação da liquidação do contrato e correlação entre a motivação e o retorno da operação: 
Tabela 1

\section{Motivos para Antecipar a Liquidação do NDF e sua Relação com o Retorno}

\begin{tabular}{ll}
\hline Motivo & Correlação com o retorno da operação \\
\hline 1. Extinção da exposição & Nula \\
2. Mudança na exposição & Nula \\
3. Antecipação de caixa, mantendo o hedge & Positiva \\
4. Especulação ex-post & Positiva \\
5. Especulação ex-ante & Positiva, nula ou negativa \\
\hline
\end{tabular}

De acordo com o racional apresentado acima, a identificação de indícios de especulação não pode ser feita operação por operação, mas sim estatisticamente, para o conjunto das operações LA. Assim, nossa metodologia se baseia na comparação entre as distribuições de retorno das operações LA e LDP. Conforme o raciocínio exposto, se a distribuição de retornos das operações LA apresentar uma maior proporção de valores positivos do que as LDP, temos evidência de que os motivos 1 e 2 não podem explicar a totalidade das antecipações. Se, além disso, houver outra evidência de que o número de reversões é pouco representativo, então temos mais uma evidência de que uma das formas de especulação (ex-ante ou ex-post) explica pelo menos uma parcela das antecipações. Dessa forma, formula-se a seguinte hipótese nula: $\mathrm{H}_{0}$ : A proporção de operações LA com resultado positivo não é maior do que a proporção de operações LDP com resultado positivo.

A rejeição dessa hipótese nula implica que as antecipações são explicadas, pelo menos em parte, por motivos especulativos. Vale destacar que, em caso de rejeição da hipótese nula, não é possível, com essa metodologia, distinguir entre especulação ex-ante e ex-post.

As comparações entre as distribuições de retorno são feitas não só para a população completa de operações, mas também para dois períodos amostrais distintos: o primeiro período, de 2003 a 2008, foi marcado por uma contínua valorização do Real. Mais importante, ao final de 2008, houve o anúncio de grandes perdas, com derivativos cambiais, por muitas empresas brasileiras. A partir de então, seguiuse uma série de mudanças regulatórias na percepção de risco de investidores, que passaram a monitorar mais fortemente as operações com derivativos. No segundo período analisado, de 2009 a 2011, também houve predominantemente uma apreciação do Real mais uma variação na direção do movimento da taxa de câmbio. Doravante, utilizaremos os termos pré-crise e pós-crise para nos referirmos ao primeiro e ao segundo período de análise. Finalmente, a análise é feita ainda separando entre as operações de compra e venda de moeda estrangeira (resultados não reportados e disponíveis sob requisição).

\section{Descrição da base de dados}

A Figura 1 mostra a evolução mensal (pela data de liquidação) das operações de NDF que compõem a base de dados, bem como o retorno mensal da taxa média de câmbio no período amostral (operações liquidadas entre janeiro de 2003 e dezembro de 2011). 


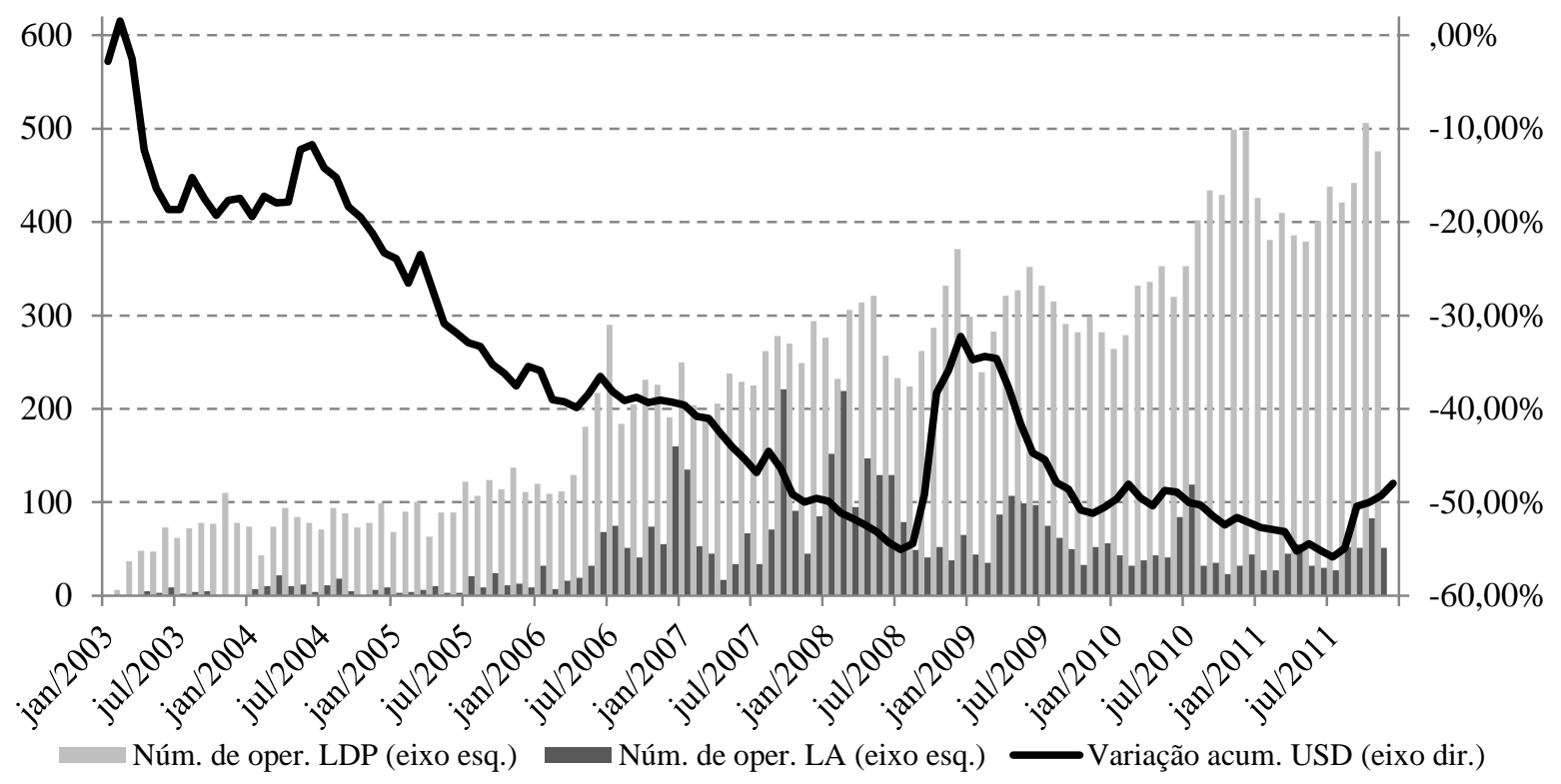

Figura 1. Quantidade Mensal de Operações de Termo de Moedas Liquidadas.

Há distinção entre liquidações antecipadas (barras escuras), liquidações na data prevista (barras claras) e retorno mensal acumulado do USD (linha - cálculo feito a partir de valores médios mensais de Ptax do Bacen).

Fonte: Elaboração própria.

Para cada operação LA, calculou-se a razão entre o prazo efetivo da operação (número de dias corridos desde a abertura da operação até o pedido de liquidação antecipada) e o prazo originalmente acordado entre as partes. A Figura 2 mostra a distribuição dessa medida. Pode-se verificar que não há nenhuma concentração acentuada para o momento em que ocorrem as reversões, embora a distribuição apresente uma ligeira concentração próxima do início e do final do contrato.

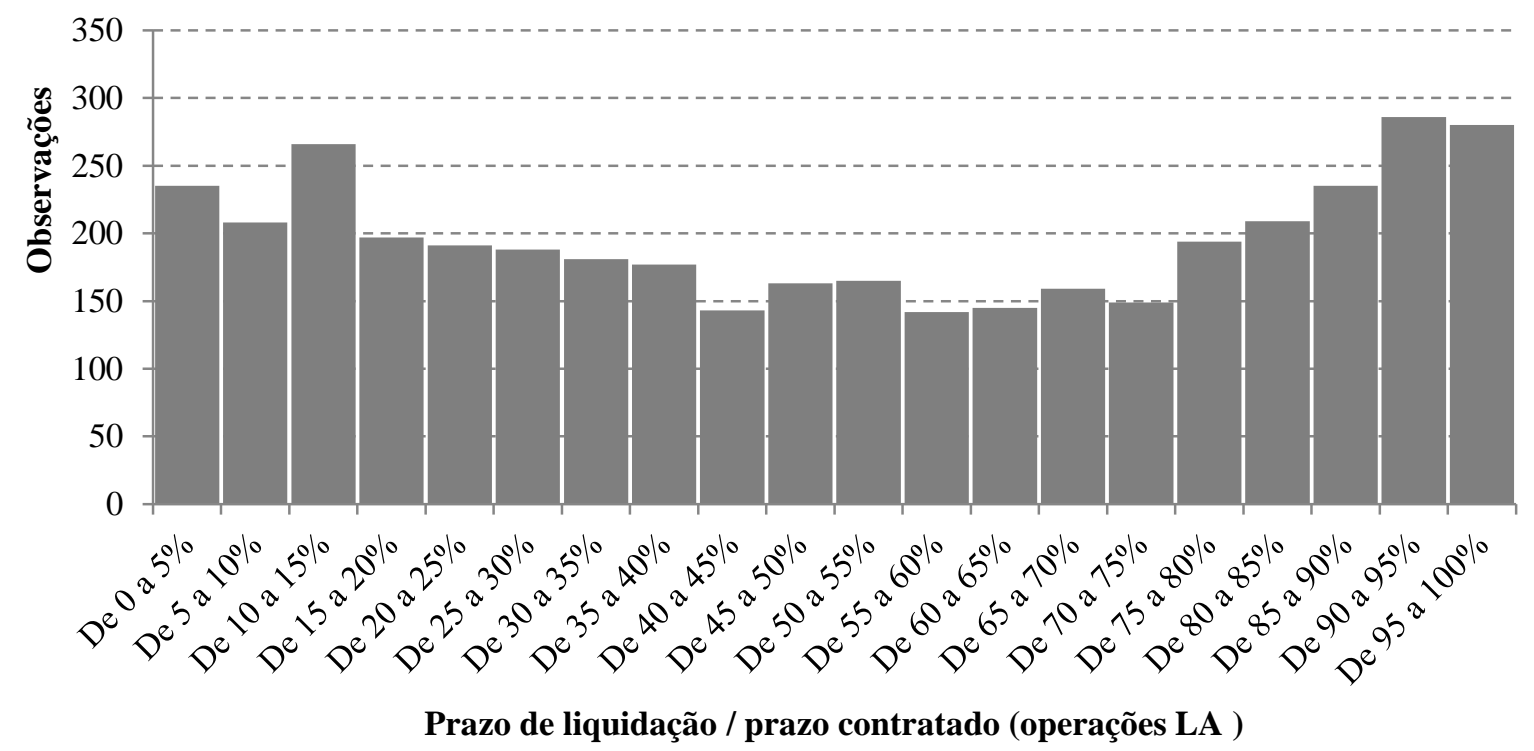

Figura 2. Prazo Decorrido até a Liquidação Antecipada da Operação, em Relação ao Prazo Total Contratado.

Fonte: Elaboração própria.

\section{Estatísticas descritivas}

$\mathrm{Na}$ comparação entre as características relativas às LDP e às LA, mostrada na Tabela 2, podemos encontrar algumas diferenças relevantes. Verificamos que as operações liquidadas 
antecipadamente referiam-se mais a operações de venda de moeda estrangeira: enquanto $23,2 \%$ das operações de venda foram revertidas, apenas $8,8 \%$ das operações de compra tiveram liquidação antecipada (diferença entre proporções estatisticamente significativa a menos de $1 \%$ ). Isso pode estar relacionado a uma diferença na atuação da empresa de acordo com o seu perfil (exportador ou importador), mas é bastante razoável imaginar que o cenário de mercado (valorização ou desvalorização do Real) também possa ter alguma influência nisso. Ao analisar em separado os períodos pré e pós-crise, verifica-se que a proporção de operações de venda de moeda estrangeira que são liquidadas antecipadamente é maior do que a proporção de operações de compra antecipadas em ambos os períodos. No entanto, no período pré-crise, a diferença é muito mais drástica: as operações de venda respondem por $80,3 \%$ do total de antecipações, contra $67,3 \%$ no segundo período.

Tabela 2

Quantidade e Percentual das Operações com Liquidação na Data Prevista (LDP) e Liquidações Antecipadas (LA) - Compra ou Venda de Moeda Estrangeira

\begin{tabular}{lcccccc}
\hline & \multicolumn{2}{c}{ 2003-2011 } & \multicolumn{2}{c}{ 2003 - 2008 } & \multicolumn{2}{c}{ 2009-2011 } \\
\cline { 2 - 7 } & Venda & Compra & Venda & Compra & Venda & Compra \\
\hline \multirow{2}{*}{ LDP } & 12.111 & 12.559 & 6.800 & 4.561 & 5.311 & 7.998 \\
& $(49,1 \%)$ & $(50,9 \%)$ & $(59,9 \%)$ & $(40,1 \%)$ & $(39,9 \%)$ & $(60,1 \%)$ \\
\multirow{2}{*}{ LA } & 3.667 & 1.207 & 2.394 & 589 & 1.273 & 618 \\
& $(75.2 \%)$ & $(24,8 \%)$ & $(80,3 \%)$ & $(19,7 \%)$ & $(67,3 \%)$ & $(32,7 \%)$ \\
\hline
\end{tabular}

$\mathrm{Na}$ Tabela 3, verifica-se que as operações liquidadas antecipadamente também têm valores nominais maiores do que as operações LDP em ambos os períodos, tanto nas operações de compra de moeda estrangeira, quanto nas de venda (diferença de média e mediana estatisticamente significativa a pelo menos de 10\%).

Tabela 3

Estatísticas Descritivas do Valor Nominal das Operações Liquidadas no Período, Separadas por Posição Assumida pela Empresa e por Tipo de Liquidação (LA ou LDP)

\begin{tabular}{|c|c|c|c|c|c|c|c|c|}
\hline & \multicolumn{4}{|c|}{ 2003-2008 } & \multicolumn{4}{|c|}{ 2009-2011 } \\
\hline & \multicolumn{2}{|c|}{ Venda } & \multicolumn{2}{|c|}{ Compra } & \multicolumn{2}{|c|}{ Venda } & \multicolumn{2}{|c|}{ Compra } \\
\hline & LDP & LA & LDP & $\mathbf{L A}$ & LDP & $\mathbf{L A}$ & LDP & $\mathbf{L A}$ \\
\hline $\mathbf{N}^{0}$ Observações & 6.800 & 2.394 & 4.561 & 589 & 5.311 & 1.273 & 7.998 & 618 \\
\hline Média (R\$ mil) & 3.003 & 7.128 & 4.069 & 18.445 & 4.074 & 5.145 & 3.465 & 6.332 \\
\hline Mediana (R\$ mil) & 910 & 1.614 & 869 & 1.598 & 901 & 938 & 432 & 939 \\
\hline Desvio-Padrão (R\$ mil) & 10.821 & 25.832 & 12.798 & 68.825 & 17.454 & 18.769 & 18.107 & 38.613 \\
\hline Estatística $z$ & \multicolumn{2}{|c|}{$7,813^{* * *}$} & \multicolumn{2}{|c|}{$5,069^{* * * *}$} & \multicolumn{2}{|c|}{$2,036^{* *}$} & \multicolumn{2}{|c|}{$1,846^{*}$} \\
\hline Estatística $u$ & \multicolumn{2}{|c|}{$15,611^{* * *}$} & \multicolumn{2}{|c|}{$5,851^{* * * *}$} & \multicolumn{2}{|c|}{$4,160^{* * *}$} & \multicolumn{2}{|c|}{$7,034^{* * *}$} \\
\hline
\end{tabular}

Nota. Testamos se a diferença entre o valor médio das operações LA e LDP é significante, assumindo distribuição normal dos valores. Para verificar se o resultado não está sendo influenciado por poucos valores extremos, testamos também para a diferença de medianas utilizando a estatística u do teste de Mann-Whitney (também conhecido como Teste de Soma de Postos de Wilcoxon). Fonte: Elaboração própria.

Os símbolos $* * *, * * \mathrm{e} *$ indicam significância a $1 \%, 5 \%$ e $10 \%$, respectivamente. 


\section{Retorno do contrato para a empresa}

Os retornos para o cliente variam de $+118 \%$ a $-110 \%$ do valor nocional da operação. Comparando-se médias, medianas e médias ponderadas entre os retornos dos dois subgrupos (teste unicaudal para retorno das operações LA maior que das LDP), rejeitam-se as hipóteses de que são iguais no período 2003-2008, sempre a níveis de significância inferiores a $1 \%$. No entanto, para o período 2003-2009, verifica-se o contrário: o retorno das operações LDP é maior (em média, mediana e média ponderada) do que o das LA.

Tabela 4

Retorno das Operações Liquidadas, Separados entre os Tipos de Liquidação (LA e LDP) e Período

\begin{tabular}{|c|c|c|c|c|}
\hline & \multicolumn{2}{|c|}{ 2003-2008 } & \multicolumn{2}{|c|}{ 2009-2011 } \\
\hline & LDP & LA & LDP & LA \\
\hline Média & $0,33 \%$ & $2,77 \%$ & $1,29 \%$ & $-0,04 \%$ \\
\hline Média ponderada & $0,21 \%$ & $1,40 \%$ & $1,28 \%$ & $-2,00 \%$ \\
\hline Mediana & $0,39 \%$ & $1,86 \%$ & $1,20 \%$ & $0,85 \%$ \\
\hline Estatística $t$ & \multicolumn{2}{|c|}{$15,41^{* * * *}$} & \multicolumn{2}{|c|}{$-6,34$} \\
\hline Estatística $u$ & \multicolumn{2}{|c|}{$17,029^{* * *}$} & \multicolumn{2}{|c|}{$-3,477$} \\
\hline
\end{tabular}

Nota. Testamos se a média e a mediana de retorno das operações LA são maiores que para as operações LDP (teste unicaudal), assumindo distribuição normal dos valores. Fonte: Elaboração própria.

O símbolo *** indica significância a $1 \%$.

Em seguida, testamos nossa hipótese principal. Se houver diferença estatisticamente significativa na proporção de operações com retorno positivo para o cliente entre as operações LA e LDP, então pelo menos uma parcela das antecipações se dá por motivos especulativos. Pode-se argumentar que resultados de baixo valor financeiro sejam considerados pela empresa como irrelevantes. É impossível determinar objetivamente o que é um retorno irrelevante. Uma vez que a escolha do retorno para comparação das operações LDPs e LAs é bastante arbitrário, testamos se a proporção de operações com retorno acima de determinado valor percentual é diferente entre as operações LDPs e LAs. Como valor percentual de referência de retorno, usamos os seguintes cortes: 0, $1 \%, 2 \%, 3 \%, 4 \%$ e $5 \%$.

Os resultados da Tabela 5 mostram que, no período pré-crise, as proporções de operações LA com retornos superiores a $0,1 \%, 2 \%$ e $3 \%$ são maiores do que as proporções de operações LDP com esses mesmos níveis de retorno (diferença estatisticamente significativa a 1\%). Para retornos de $4 \%$ ou mais, as proporções não são estatisticamente distintas. Esses resultados indicam que as hipóteses de que a liquidação antecipada das operações é motivada unicamente por modificação ou extinção da exposição inicial é refutada, como argumentado acima.

Já no período pós-crise, observa-se que a proporção de operações LA e LDP é estatisticamente diferente apenas para retornos acima de zero, sendo indistintas as proporções de retornos de $1 \%$ ou mais.

Tomados em conjunto, os resultados obtidos para os períodos pré-crise e pós-crise indicam que houve uma mudança no padrão de uso de derivativos após a crise de 2008. Primeiro, a proporção de operações liquidadas antecipadamente foi drasticamente reduzida no período pós-crise em comparação com o período anterior. Segundo, verifica-se que, ao passo em que no período pré-crise as decisões de antecipações são positivamente correlacionadas ao retorno - indicando que parcela significativa das antecipações não pode ser explicada por mudança ou extinção da exposição -, no período pós-crise, as 
antecipações não são correlacionadas ao retorno da operação, não sendo possível refutar que as antecipações se deveram a mudanças na exposição operacional.

Tabela 5

Comparação entre Proporção de Retornos Positivos: LDP x LA

\begin{tabular}{|c|c|c|c|c|c|c|}
\hline \multirow{3}{*}{$\begin{array}{l}\text { Corte de } \\
\text { retorno }\end{array}$} & \multicolumn{3}{|c|}{ 2003-2008 } & \multicolumn{3}{|c|}{ 2009-2011 } \\
\hline & No. LDP & No. LA & $\begin{array}{l}\text { Estatística - } \\
\text { Teste de } \\
\text { Proporções }\end{array}$ & No. LDP & No. LA & $\begin{array}{l}\text { Estatística - } \\
\text { Teste de } \\
\text { Proporções }\end{array}$ \\
\hline & $\begin{array}{l}\text { (\% do total } \\
\text { de LDP) }\end{array}$ & $\begin{array}{l}\text { (\% do total } \\
\text { de LA) }\end{array}$ & p-valor & $\begin{array}{l}\text { (\% do total } \\
\text { de LDP) }\end{array}$ & $\begin{array}{l}\text { (\% do total } \\
\text { de LA) }\end{array}$ & p-valor \\
\hline \multirow[t]{2}{*}{$>0 \%$} & 5.974 & 2.381 & $22,79^{* * * *}$ & 7.805 & 1.144 & $2,44^{* * *}$ \\
\hline & $52,58 \%$ & $79,82 \%$ & $<0,01 \%$ & $58,64 \%$ & $62,45 \%$ & $0,73 \%$ \\
\hline \multirow[t]{2}{*}{$>1 \%$} & 5.161 & 1.857 & $12,44^{* * * *}$ & 6.853 & 922 & $-0,66$ \\
\hline & $45,43 \%$ & $62,25 \%$ & $<0,01 \%$ & $51,49 \%$ & $50,33 \%$ & $74,7 \%$ \\
\hline \multirow[t]{2}{*}{$>2 \%$} & 4.429 & 1.446 & $6,37^{* * *}$ & 5.858 & 761 & $-1,30$ \\
\hline & $38,98 \%$ & $48,47 \%$ & $<0,01 \%$ & $44,02 \%$ & $41,54 \%$ & $90,2 \%$ \\
\hline \multirow[t]{2}{*}{$>3 \%$} & 3.861 & 1.142 & $2,68^{* * *}$ & 4.985 & 633 & $-1,42$ \\
\hline & $33,98 \%$ & $38,28 \%$ & $0,37 \%$ & $37,46 \%$ & $34,55 \%$ & $92,3 \%$ \\
\hline \multirow[t]{2}{*}{$>4 \%$} & 3.374 & 922 & 0,71 & 4.241 & 467 & $-2,82$ \\
\hline & $29,70 \%$ & $30,91 \%$ & $23,85 \%$ & $31,87 \%$ & $25,49 \%$ & $99,8 \%$ \\
\hline \multirow[t]{2}{*}{$>5 \%$} & 2.924 & 755 & $-0,24$ & 3.604 & 398 & $-2,30$ \\
\hline & $25,74 \%$ & $25,31 \%$ & $59,47 \%$ & $27,08 \%$ & $21,72 \%$ & $98,9 \%$ \\
\hline $\begin{array}{c}\text { Todas as } \\
\text { Observações }\end{array}$ & 11.361 & 2.983 & - & 13.309 & 1.832 & - \\
\hline
\end{tabular}

Nota. Essa tabela mostra as proporções de operações LA e LDP com retorno acima de cada um dos cortes exibidos. Testamos se a proporção de operações LA com resultado acima do corte indicado é maior que a proporção de operações LDP para o mesmo corte de retorno (teste unicaudal). Fonte: Elaboração própria.

O símbolo ${ }^{* * * *}$ indica significância estatística a $1 \%$.

Finalmente, fizemos o mesmo procedimento, separando-se por operações de compra e venda de moeda estrangeira (resultados não reportados). As inferências sobre especulação no período pré-crise foram mantidas tanto para as operações de compra quanto de venda, o que indica que nossos resultados não se devem ao longo período de apreciação do Real no período pré-crise.

A seguir, identificamos se as operações com liquidação antecipada foram seguidas de reset da operação. No período pré-crise, do universo de eventos de liquidação antecipada, encontramos a situação em que a companhia realizou, no mesmo dia, uma nova operação com o banco em 332 $(11,1 \%)$ dos casos, dos quais $201(60,5 \%)$ das antecipações geraram resultado positivo. No período pós-crise, $14 \%$ das operações antecipadas foram seguidas de outra operação no mesmo dia. Podemos considerar esses percentuais pouco representativos em relação ao total de antecipações.

Repetindo a mesma análise, mas desta vez considerando o prazo de até 5 dias úteis após a liquidação antecipada, encontramos que apenas 25\% (pré-crise) e $24 \%$ (pós-crise) das empresas voltaram a contratar operações com o banco nesse período. 
Finalmente, ao repetir os testes de proporção com a exclusão das operações LA que foram seguidas de qualquer tipo de reset, as inferências derivadas dos resultados da tabela 4 não se alteram em relação aos testes feitos com a amostra completa (resultados não reportados).

\section{Evidências adicionais}

Adicionalmente aos testes reportados anteriormente, verificamos o caminho que o ativo subjacente ao derivativo (a cotação da moeda estrangeira) seguiu durante a vigência do contrato até a data da antecipação, para verificarmos se a liquidação antecipada ocorreu quando o valor de mercado do contrato de NDF estava no momento de maior valor até então. Caso isso se verifique, essa pode ser uma forte indicação de que os gestores podem estar se aproveitando de valores positivos nos contratos para realizarem os resultados positivos, deixando a empresa exposta ao risco que ensejou a operação ao liquidar antecipadamente o contrato.

A cotação, a termo de uma moeda em relação à outra, segue uma função de não arbitragem entre as taxas de juros de ambas as moedas. Assim, a taxa de câmbio de uma moeda estrangeira para uma data futura, assumindo a ausência de custos de transação, é dada por:

$$
F W D_{t, T}=\operatorname{Spot}_{t} \cdot \frac{\left(1+y_{\text {local }}\right)^{(T-t)}}{\left(1+y_{\text {externa }}\right)^{(T-t)}}
$$

em que:

$F W D_{t, T}$ é a taxa forward (a termo) de câmbio contratada na data $t$ com vencimento numa data futura $T$;

. $y_{\text {local }}$ é a taxa de juros pré-fixada da moeda local na data $t$ para a maturidade $T$;

- $y_{\text {externa }}$ é a taxa de juros pré-fixada da moeda estrangeira na data $t$ para a maturidade $T$.

Por valor a mercado do derivativo, entendemos o resultado (a valor presente) da liquidação desse contrato em determinado momento.

Uma vez que esse procedimento necessita de extensa base de dados histórica, conduz-se esse teste apenas para as operações em dólar americano, que representam a imensa maioria das operações (do total de 4815 operações LA, perdemos apenas 142 observações com esse procedimento). Para tal, utilizamos dados das curvas de juros (taxas de juros para diferentes maturidades) em reais e dólares utilizados pelo banco e a taxa de câmbio diária média divulgada pelo Banco Central (Ptax) para construir, para cada dia, a partir do início de cada uma das operações, toda a curva de taxas a termo de dólar ${ }^{(2)}$.

O resultado para o período pré-crise parece em linha com a hipótese de especulação: das 2.900 antecipações observadas nesse período, nada menos do que $48 \%$ delas ocorreram no dia em que o valor do contrato, marcado a mercado, atingiu seu ponto máximo na vigência da operação até então. Ao investigar se a liquidação foi feita não exatamente no dia de ponto máximo, porém nos dias imediatamente subsequentes (caso em que o gestor acompanha a evolução do mercado e decide pela antecipação apenas após verificar que o ponto de máximo foi atingido, ou seja, que o valor a mercado não prosseguiu em trajetória ascendente), encontramos então que, em $62,4 \%$ das antecipações, o valor máximo do contrato havia sido atingido até 3 dias úteis antes da reversão da operação. Ainda como contraponto, verificamos que apenas $7,7 \%$ do total de operações foram antecipadas no dia de mínimo valor de mercado no período pré-crise. Já no período pós-crise, apenas $22 \%$ das operações foram liquidadas antecipadamente na data de maior valor de mercado, e 33\% delas nos três dias após atingir o valor de mercado máximo. 


\section{Especulação por perfil de empresa}

Para as operações liquidadas entre 2003 e 2008, tivemos acesso ainda às seguintes características das empresas contratantes: (a) a nacionalidade da empresa (doméstica ou estrangeira); (b) o tipo de capital da empresa (aberto ou fechado); (c) se a empresa é exportadora/importadora ou não (dados da Secretaria de Comércio Exterior do Governo Federal - Secex).

As empresas analisadas foram divididas em 4 grupos, conforme a nacionalidade do controle e a negociação em bolsas de valores ou não. Finalmente, identificou-se que 50\% das empresas tinham realizado importação no período e $74 \%$ realizaram exportação, sendo que $82 \%$ tinham registro de pelo menos uma dessas atividades. Embora o comércio exterior não seja o único fator a gerar exposição cambial (empréstimos, ativos, receitas ou custos denominados em moeda estrangeira, por exemplo, também podem gerar exposição cambial), esses resultados são indicativos de que as companhias que contratam operações de NDF têm alguma espécie de exposição cambial.

Nesta seção, repetimos os testes de proporções, comparando o percentual de LDP e LA com retornos positivos para cada um dos 4 perfis de empresa. Os testes são feitos apenas para o período 2003-2008 por conta da restrição nos dados. Nos resultados reportados na Tabela 6, podemos verificar que a proporção de operações LA com retorno superior a $1 \%$ é maior que a proporção de LDP com o mesmo retorno (estatisticamente significante a 1\%), independente do perfil da empresa. As operações das empresas multinacionais de capital aberto são aquelas que apresentam maior diferença na comparação dos resultados das LDPs e LAs.

Nas empresas domésticas de capital aberto, a diferença de proporção entre operações lucrativas LA e LDP é menor, e ocorre com significância estatística apenas para operações de retorno até $1 \%$. Isso indica menor propensão ao comportamento especulativo, o que é coerente com a maior divulgação de informações e melhores práticas de governança que as companhias listadas em bolsa precisam adotar.

As empresas com controle estrangeiro são aquelas que apresentam maiores indícios de comportamento especulativo. Mais ainda, as empresas nas quais encontramos maior relação entre a liquidação antecipada e o resultado positivo da operação são as multinacionais com ações negociadas em bolsa. Isso é, até certo ponto, surpreendente, à medida que as empresas multinacionais tendem a ser maiores e apresentar melhores instrumentos de governança corporativa. Embora não seja possível inferir exatamente as motivações dessas empresas ao utilizar derivativos, esse resultado é consistente com o argumento de Rossi (2012): numa subsidiária de empresa estrangeira, por ter exposição mais intensiva a outras moedas, os gestores acreditam ter maior vantagem informacional e expertise quanto ao mercado de câmbio. O incentivo à tomada de posições especulativas não depende da real existência dessa vantagem, mas sim da crença do gerente em sua capacidade de gerar valor através de tais operações.

Somando-se a isso, podemos imaginar que a maior distância entre a gerência local e o controlador da empresa desfavoreça a identificação de qualquer comportamento especulativo. Isso pode ser intensificado na medida em que a companhia tem, naturalmente, seu balanço exposto à variação cambial (exposição não apenas operacional, mas também contábil). Se a empresa não tem uma política de hedge bem definida, ou instrumentos de governança que garantam que tal política seja implementada e reportada conforme planejada, essa exposição natural pode ser utilizada para justificar tanto a inexistência de hedge (se o administrador não o faz, a multinacional estará exposta por causa de sua própria característica intrínseca - ter negócios em vários países), quanto a utilização de derivativos para mitigação do risco cambial. Essa facilidade em justificar suas ações poderia incentivar o administrador que tem propensão ao risco a tomar posições especulativas (seja ao contratar uma operação com propósito especulativo, seja ao deliberadamente liquidar antecipadamente uma operação de hedge e manter a exposição operacional). 
Tabela 6

Resultados dos Testes Aplicados para Diferentes Cortes de Lucro, por Grupos de Empresas (2003 a 2008)

\begin{tabular}{|c|c|c|c|c|c|c|c|c|c|}
\hline \multirow{3}{*}{$\begin{array}{l}\text { Corte de } \\
\text { Retorno }\end{array}$} & & \multicolumn{4}{|c|}{ Controle Doméstico } & \multicolumn{4}{|c|}{ Controle Doméstico } \\
\hline & & \multicolumn{2}{|c|}{ Capital Fechado } & \multicolumn{2}{|c|}{ Capital Aberto } & \multicolumn{2}{|c|}{ Capital Fechado } & \multicolumn{2}{|c|}{ Capital Aberto } \\
\hline & & LDP & LA & LDP & LA & LDP & LA & LDP & LA \\
\hline \multirow{3}{*}{$>0 \%$} & Num. Oper. & 2.916 & 1.601 & 557 & 451 & 519 & 92 & 1.982 & 237 \\
\hline & Proporção & $51,6 \%$ & $81,6 \%$ & $55,6 \%$ & $77,8 \%$ & $54,2 \%$ & $82,1 \%$ & $52,8 \%$ & $72,0 \%$ \\
\hline & Estatística & \multicolumn{2}{|c|}{$19,62^{* * *}$} & \multicolumn{2}{|c|}{$7,28^{* * *}$} & \multicolumn{2}{|c|}{$5,00^{* * *}$} & \multicolumn{2}{|c|}{$5,61^{* * *}$} \\
\hline \multirow{3}{*}{$>1 \%$} & Num. Oper. & 2.525 & 1.217 & 465 & 340 & 438 & 73 & 1.733 & 227 \\
\hline & Proporção & $44,7 \%$ & $62,0 \%$ & $46,4 \%$ & $58,6 \%$ & $45,7 \%$ & $65,2 \%$ & $46,2 \%$ & $69,0 \%$ \\
\hline & Estatística & \multicolumn{2}{|c|}{$9,93^{* * *}$} & \multicolumn{2}{|c|}{$3,42^{* * *}$} & \multicolumn{2}{|c|}{$3,08^{* * *}$} & \multicolumn{2}{|c|}{$6,47^{* * *}$} \\
\hline \multirow{3}{*}{$>2 \%$} & Num. Oper. & 2.195 & 943 & 378 & 238 & 362 & 59 & 1.494 & 206 \\
\hline & Proporção & $38,9 \%$ & $48,1 \%$ & $37,7 \%$ & $41,0 \%$ & $37,8 \%$ & $52,7 \%$ & $39,8 \%$ & $62,6 \%$ \\
\hline & Estatística & \multicolumn{2}{|c|}{$4,80^{* * *}$} & \multicolumn{2}{|c|}{0,82} & \multicolumn{2}{|c|}{$2,17^{* *}$} & \multicolumn{2}{|c|}{$6,22^{* * *}$} \\
\hline \multirow{3}{*}{$>3 \%$} & Num. Oper. & 1.927 & 739 & 332 & 158 & 288 & 50 & 1.314 & 195 \\
\hline & Proporção & $34,1 \%$ & $37,7 \%$ & $33,1 \%$ & $27,2 \%$ & $30,1 \%$ & $44,6 \%$ & $35,0 \%$ & $59,3 \%$ \\
\hline & Estatística & \multicolumn{2}{|c|}{$1,72^{* *}$} & \multicolumn{2}{|c|}{$-1,32$} & \multicolumn{2}{|c|}{$2,05^{* *}$} & \multicolumn{2}{|c|}{$6,55^{* * * *}$} \\
\hline \multirow{3}{*}{$>4 \%$} & Num. Oper. & 1.698 & 607 & 294 & 105 & 225 & 35 & 1.157 & 175 \\
\hline & Proporção & $30,1 \%$ & $30,9 \%$ & $29,3 \%$ & $18,1 \%$ & $23,5 \%$ & $31,2 \%$ & $30,8 \%$ & $53,2 \%$ \\
\hline & Estatística & \multicolumn{2}{|c|}{0,40} & \multicolumn{2}{|c|}{$-2,28$} & \multicolumn{2}{|c|}{1,00} & \multicolumn{2}{|c|}{$5,88^{* * *}$} \\
\hline & Num. Oper. & 1.469 & 481 & 252 & 80 & 170 & 27 & 1.033 & 167 \\
\hline$>5 \%$ & Proporção & $26,0 \%$ & $24,5 \%$ & $25,1 \%$ & $13,8 \%$ & $17,7 \%$ & $24,1 \%$ & $27,5 \%$ & $50,8 \%$ \\
\hline & Estatística & -0, & & -2 & & & & & \\
\hline & Operações & 7.6 & & & & & & & \\
\hline Total & LDP & 5.6 & & 1.0 & & & & & \\
\hline & LA & 1.9 & & & & & & & \\
\hline
\end{tabular}

Nota. Estabelecemos diferentes percentuais mínimos de retorno para o cliente (resultado / valor da operação), e para cada um desses cortes, verificamos a proporção de operações LDP e LA que resultaram em lucro maior ou igual ao estabelecido. Em seguida, realizamos o teste de proporções de duas amostras para verificar se a proporção de LA com lucro maior que o corte, em relação ao total de operações LA, é significativamente maior do que a proporção de operações LDP com lucro acima do corte. Fonte: Elaboração própria.

\section{Antecipações e perdas em potencial}

Voltamos a ressaltar que, caso os derivativos liquidados antecipadamente tenham sido inicialmente contratados para hedge (ou seja, existe uma contrapartida dessa exposição em moeda que motivou a contratação do derivativo, de tal forma que o ganho no derivativo compensa uma perda operacional da empresa e vice-versa, caracterizando uma especulação ex-post), a perda da empresa não se daria nas operações com derivativos, mas, sim, na exposição operacional que deixou de ser protegida. Num exemplo simples, assumamos que a empresa tome um financiamento em moeda estrangeira, e faça o hedge dessa dívida por meio da compra de moeda a termo. Se, no período do financiamento, a moeda estrangeira se aprecia $10 \%$, o resultado seria uma perda financeira por variação cambial no passivo da empresa, e um lucro equivalente no derivativo. Se, no entanto, o 
derivativo foi liquidado antecipadamente quando a apreciação da moeda era apenas 5\%, os 5\% restantes significaram uma perda por variação cambial no endividamento da empresa, não compensada por nenhum resultado financeiro positivo.

Embora não seja foco principal desse trabalho identificar se essas operações geram ou não valor, é possível verificar qual teria sido o resultado para a empresa se a reversão não ocorresse, e as operações fossem levadas até o vencimento original (novamente, pela necessidade de dados para essa análise, verificaremos apenas para as operações em dólares americanos). Reconhecemos que as estimativas que fazemos a esse respeito são bastante imprecisas, pois assumem que em nenhuma das liquidações antecipadas a motivação foi a modificação ou a extinção da exposição inicial. Ainda assim, acreditamos ser ilustrativo mostrar as perdas em potencial da antecipação da liquidação no resultado operacional da empresa.

Nas antecipações feitas no período pré-crise, em $65,4 \%$ dos casos, a empresa teria obtido um resultado melhor se não houvesse liquidado antecipadamente o contrato; a reversão levou a companhia a abrir mão, em média, de resultados equivalentes a aproximadamente $6 \%$ do valor nocional da operação. Essa seria a perda da empresa com o efeito da variação cambial sobre suas exposições operacionais, assumindo que elas ainda existissem após a extinção do hedge. Já no período pós-crise, as antecipações levaram a firma a abrir mão de $1,4 \%$ do valor da operação em média, sendo que em $60,1 \%$ das antecipações o resultado teria sido melhor caso a operação tivesse sido mantida até o vencimento.

A Figura 3 traz os resultados hipotéticos das operações LA caso fossem mantidas até o vencimento. Também é imediato verificar que a liquidação antecipada diminui a variabilidade dos retornos, uma vez que a distribuição dos retornos hipotéticos apresenta maior dispersão do que a dos retornos efetivos das operações.

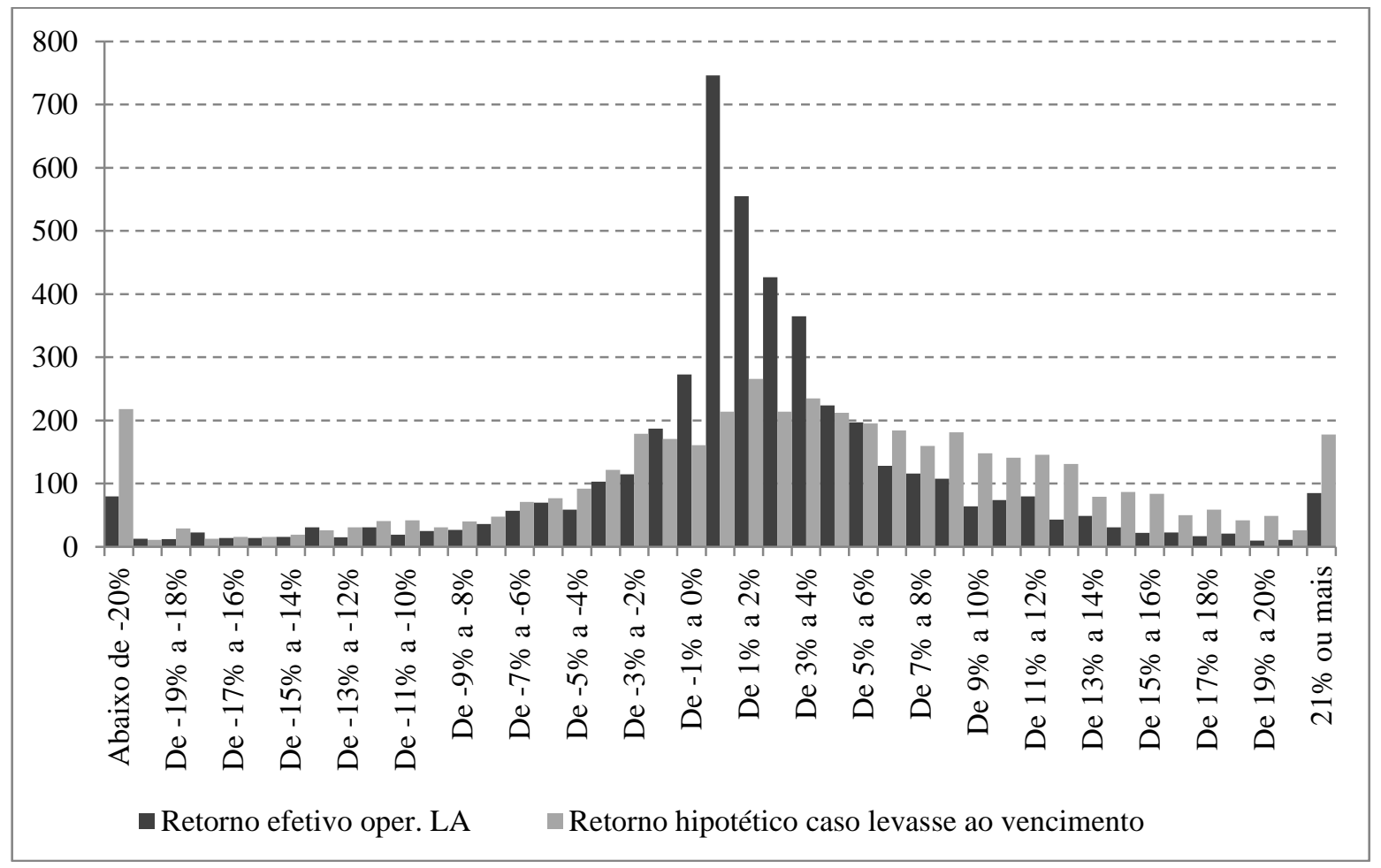

Figura 3. Distribuição de Resultados das Operações LA e Distribuição Hipotética Caso as Mesmas Operações Fossem Liquidadas na Data de Vencimento Original.

As barras mostradas como LDP hipotético representam o retorno das operações das quais a empresa abriu mão ao liquidar antecipadamente a operação. Fonte: Elaboração própria. 


\section{Conclusão}

A literatura financeira ainda não possui um arcabouço teórico-empírico que seja capaz de explicar completamente o comportamento das empresas em relação às práticas de uso de derivativos. As mais recentes pesquisas apontam para a relevância das chamadas visões de mercado no processo de tomada de decisão. Os motivos e as implicações do uso de visões de mercado ao tomar posições em derivativos permanecem sendo discutidos sem que uma teoria satisfatória tenha emergido.

Casos anedóticos não faltam, quase sempre revelados de modo inesperado e problemático, às custas de perdas de milhões ou bilhões de dólares, como observado no Brasil na segunda metade de 2008, e em diversos países em outros momentos. Ainda que as ações tomadas pelas companhias, o cenário de mercado e os instrumentos utilizados difiram entre as situações, podemos encontrar dois pontos em comum entre os casos de perdas: em todos eles, está presente, em algum grau, uma aposta das companhias de que determinada situação de mercado iria perdurar; e, quando da mudança de cenário, as empresas não estavam preparadas para se adequarem tão rapidamente a essa nova situação de forma a limitar as perdas.

Neste trabalho, abordamos a questão de maneira diferente dos estudos anteriores sobre o assunto. Observando as operações das companhias com um dos mais simples e mais utilizados instrumentos derivativos - contratos a termo de moedas, NDF, contratadas junto a um dos bancos líderes no mercado brasileiro de derivativos cambiais, obtivemos indicativos sobre como o comportamento especulativo não esteve limitado, no período de 2003 a 2008, a poucas grandes apostas, mas, sim, ligado de forma intrínseca à decisão cotidiana do administrador. São encontradas fortes evidências de que as empresas realizaram lucros nessas operações encerrando antecipadamente seus contratos, ao passo que existe uma proporção substancialmente mais baixa de operações encerradas antecipadamente com prejuízo no período de 2003 a 2008. Já no período de 2009 a 2011, não se identifica tal comportamento especulativo nas operações do dia a dia que analisamos. Acreditamos que os eventos de grandes prejuízos de empresas brasileiras no final de 2008 possam ter servido de alerta para que investidores, reguladores, conselheiros e até os próprios gestores financeiros e as instituições financeiras que negociam derivativos com empresas não financeiras tenham aumentado o monitoramento e a diligência na realização dessas operações, evitando a assunção de posições especulativas.

A seguir damos atenção especial aos resultados obtidos para o período 2003-2008, em que se evidenciou comportamento especulativo, pois esses são mais ilustrativos sobre o modus-operandi da tomada de posições em derivativos e sobre o potencial de perdas para as empresas.

As evidências para o período de 2003 a 2008 podem ser descritas da seguinte maneira: a companhia realizava o lucro de posições com retorno positivo, porém carregava até o vencimento operações com prejuízo. A falta de explicações alternativas para essa diferença, aliada ao fato de que, na maior parte das vezes, a reversão ocorre no momento de máximo valor presente na história do contrato, indica que o valor de mercado (ou seja, o retorno da operação) é relevante para a decisão de liquidar antecipadamente o contrato derivativo; isso indica que o tomador de decisão não tinha como única preocupação a otimização dos riscos financeiros, mas também o resultado de suas posições.

De fato, os resultados encontrados para o período 2003-2008 são consistentes com Géczy et al. (2007), cuja linha de raciocínio estabelece uma diferenciação tênue entre as operações de hedge e as especulativas, não sendo possível distinguir claramente as operações destinadas a reduzir o risco financeiro da empresa daquelas que objetivam um retorno positivo per se. Seguindo essa linha, a partir do momento em que as empresas são motivadas a utilizar derivativos para seu gerenciamento de risco, a mudança para uma atitude de tomar posições buscando resultados financeiros positivos parece ser bastante comum. Os resultados evidenciados no presente trabalho podem ser explicados se imaginarmos uma situação em que as decisões de gerenciamento de risco e especulação confundem-se nas empresas. Aparentemente, ao decidir pelo hedge, a empresa pode estar, na verdade, utilizando uma exposição existente para justificar a tomada de uma posição especulativa. 
Porém, segundo sugerem os resultados encontrados para o período 2003-2008, tal posição pode nem sempre estar sendo tomada ativamente através dos instrumentos derivativos. Nas situações analisadas neste trabalho, os indícios sugerem que a empresa pode ter tomado uma posição ativamente ao escolher o momento de desfazer o hedge e continuar com a exposição operacional pré-existente. Se for assumido que: (a) a posição inicialmente contratada é motivada por uma real exposição da empresa; e (b) a liquidação antecipada de um contrato não é motivada pela extinção dessa exposição inicial, então a posição efetivamente especulativa não foi montada a partir do momento em que a empresa contratou o derivativo, mas, sim, a partir do momento em que a empresa optou por reverter o derivativo, reassumindo sua exposição original.

Embora a primeira pressuposição seja de difícil verificação empírica, uma vez que não temos total acesso à identificação das empresas (e, portanto, a suas características em cross-section), o fato de que $82 \%$ das companhias têm histórico de importação ou exportação no período pode indicar que quase sempre existe uma exposição cambial subjacente ao hedge. Ainda assim, os 3 resultados descritos abaixo sugerem fortemente que a segunda pressuposição é bastante plausível: (a) A proporção de antecipações com lucro é substancialmente (e estatisticamente significante) maior do que a proporção de operações liquidadas no vencimento que resultam em lucro; (b) Apenas uma parcela pequena das operações revertidas são seguidas de outra operação (reset da operação), o que indica que apenas uma pequena parcela das antecipações pode ser motivada por mudança no tamanho ou no tipo de exposição, ou, ainda, pela simples antecipação de um fluxo de caixa positivo; (c) Uma parcela bastante significativa das liquidações antecipadas ocorre quando o contrato atinge seu valor máximo até então, o que não parece ter nenhuma relação com a possibilidade de extinção da exposição inicial que motivou a abertura do contrato.

Assim, os resultados para o período 2003-2008 indicam que a tomada de posições especulativas pode estar ligada às decisões cotidianas do gestor financeiro que, ao identificar oportunidade de realização de lucro na operação com derivativos, extingue a operação que inicialmente foi montada para hedge, deixando a empresa exposta a riscos. Tal resultado é relevante quando pensamos nas implicações que isso representa em termos de governança corporativa, ou seja, para a identificação, seja pelos acionistas, pelo conselho, ou pela alta administração da empresa, da real exposição ao risco assumida pela companhia.

Quando consideramos o perfil das empresas que apresentam tais indícios de especulação, encontramos um fato interessante: são as multinacionais de capital (próprio ou do controlador) negociado em bolsa que se destacaram com relação à intensidade dos indícios de especulação no período 2003-2008. Isso pode sugerir que a existência de riscos inerentes à operação e o tamanho da empresa (ou, alternativamente, uma alegada expertise na gestão financeira, que pode impactar na confiança dos administradores) podem ser fatores relevantes para a predisposição de uma empresa ao comportamento especulativo. Esses resultados são consistentes com Rossi (2012), que mostra que empresas com alegada vantagem informacional no mercado de câmbio são mais propensas a especular com derivativos.

Um cenário que agregue todos esses pontos parte do pressuposto de que as empresas que operam em mercados de diferentes moedas têm maior incentivo em fazer o hedge seletivo, provavelmente pelo fato de seu balanço estar naturalmente exposto às flutuações da moeda local. A exposição a riscos selecionados não é tomada via derivativos, mas, sim, o gestor se aproveita da exposição natural da empresa para fazer trading, decidindo quando manter a exposição hedgeada ou não. Possíveis perdas no hedge são compensadas pela posição operacional da empresa, enquanto ganhos são realizados. É, ao contrário do que recomenda Stulz (1996), uma aposta de que a cauda da distribuição em relação à sua exposição natural não vai acontecer, uma vez que a empresa perderia mais, justamente na ocorrência de eventos extremos.

Igualmente importantes são os resultados descritos para o período pós-crise (2009-2011). Nesse período, não encontramos evidência de comportamento especulativo, em linha com os resultados de Coutinho et al. (2012). Fundamentalmente, não se encontrou relação entre o valor do derivativo (ou seu retorno) e a antecipação de sua liquidação, e apenas uma pequena parcela das antecipações foram 
feitas no momento de máximo valor de mercado, o que não permite descartar a hipótese fundamental de que as antecipações podem ter sido motivadas por extinção ou modificação da exposição operacional nesse período.

Finalmente, cabe destacar que há ainda outras possibilidades de comportamento especulativo que não podem ser detectados com nossa metodologia. Por exemplo, é possível que uma operação seja contratada como especulação ex-ante (ou seja, uma aposta na direção do movimento da moeda estrangeira) e mantida até o vencimento, ou ainda que a exposição relativa a uma operação inicialmente contratada para hedge seja extinta, mas a empresa decida manter o derivativo até o vencimento por acreditar que este possa dar um retorno positivo ${ }^{(3)}$. Assim, é oportuno deixar claro que nossa metodologia permite refutar a hipótese de ausência de especulação no período 2003-2008, e não permite refutar a mesma hipótese para o período seguinte. Por isso, não somos capazes de afirmar categoricamente que não houve comportamento especulativo no período pós-crise.

As principais limitações desse estudo, descritas a seguir, estão ligadas às restrições impostas pelo banco de dados utilizado:

1. As operações analisadas foram todas contratadas junto a um único banco. Não é implausível supor que haja algum tipo de viés de seleção associado a esse fato. É possível que as empresas que contratem operações de derivativos cambiais junto a um banco específico tenham algumas características que as distingam das empresas que contratam operações similares com outros bancos. Em especial, por se tratar do maior banco de capital estrangeiro com atividades no país, com forte atuação em toda a América do Sul, é possível que estejamos lidando com uma amostra de empresas que tenham atividades mais fortemente relacionadas a esses países, ou ainda com sede nesses países, que se caracterizam por um nível de governança menor. Ainda assim, é pouco plausível que empresas mantenham posições contrárias (comprada e vendida) contratadas junto a bancos distintos, ou que liquidem uma operação junto a um banco e contratem operação similar junto a outro banco ou no mercado organizado, dado que o custo associado a fechar e a abrir uma nova posição em outro banco é bastante maior do que o de manter a posição original, ou ainda do que o de fazer o reset da operação para levantar caixa. De fato, Novaes e Oliveira (2005) mostram que o volume de derivativos contratados por empresas não financeiras no mercado de balcão é bastante superior ao volume contratado em mercados organizados;

2. Por questões de sigilo bancário, não foi possível ter acesso à identificação das empresas. Assim, não foi possível estabelecer qualquer relação das operações contratadas com as atividades operacionais das empresas e suas reais exposições cambiais, o que ajudaria a elucidar melhor as questões levantadas; nossos resultados, no entanto, independem da identificação específica de eventuais exposições que tenham motivado a contratação do derivativo.

Assim, é natural que as mitigações das limitações citadas anteriormente sejam mencionadas como possíveis tópicos para investigações futuras.

\section{Notas}

\footnotetext{
${ }^{1}$ Outros trabalhos que usam dados de operações com um único intermediário financeiro, embora com outros propósitos de investigação, são Barber, B. M., \& Odean, T. (2001). Boys will be boys: gender, overconfidence and common stock investment. Quarterly Journal of Economics, 116(1), 261-292. doi: 10.1162/003355301556400, Géczy, C. C., Musto, D. K., $\&$ Reed, A. V. (2002). Stocks are special too: an analysis of the equity lending market. Journal of Financial Economics, 66(2-3), 241-269. doi: 10.1016/S0304-405X(02)00225-8, Cohen, L., Diether, K. B., \& Malloy, C. J. (2007). Supply and demand shifts in the shorting market. The Journal of Finance, 62(5), 2061-2096. doi: 10.1111/j.1540-6261.2007.01269.x, Evans, R. B., Geczy, C. C., Musto, D. K., \& Reed, A. V. (2009). Failure is an option: impediments to short selling and options prices. Review of Financial Studies, 22(5), 1955-1980. doi: 10.2139/ssrn.423881

${ }^{2}$ Para uma pequena parcela das operações, não havia dados sobre as curvas completas (i.e., todas as maturidades em dólar e em reais). Nesses casos, foi utilizada uma interpolação linear a partir das curvas de NDF e das curvas de taxa pré em reais. Se
} 
utilizarmos esse mesmo procedimento (menos preciso para obtenção do valor de mercado) para todas as operações, os resultados são qualitativamente similares.

${ }^{3}$ Agradecemos a um dos pareceristas por apontar mais essa possibilidade de especulação.

\section{Referências}

Adam, T. R., \& Fernando, C. S. (2006). Hedging, speculation, and shareholder value. Journal of Financial Economics, 81(2), 283-309. doi: 10.1016/j.jfineco.2005.03.014

Allayannis, G., \& Ofek, E. (2001). Exchange rate exposure, hedging, and the use of foreign currency derivatives. Journal of International Money and Finance, 20(2), 273-296. doi: 10.1016/S02615606(00)00050-4

Allayannis, G., \& Weston, J. (2001). The use of foreign currency derivatives and firm market value. The Review of Financial Studies, 14(1), 243-276. doi: 10.1093/rfs/14.1.243

Bailly, N., Browne, D., Hicks, E., \& Skerrat, L. (2003). UK corporate use of derivatives. The European Journal of Finance, 9(2), 169-193. doi: 10.1080/13518470110071218

Bartram, S. M., Brown, G. M., \& Fehle, F. R. (2009). International evidence on financial derivatives usage. Financial Management, 38(1), 185-206. doi: 10.1111/j.1755-053X.2009.01033.x

Beber, A., \& Fabri, D. (2012) .Who times the foreign exchange market? Corporate speculation and CEO characteristics. Journal of Corporate Finance, 18(5), 1065-1087. doi: 10.1016/j.jcorpfin.2012.07.004

Bodnar, G. M., Hayt, G. S., \& Marston, R. C. (1998). 1998 Wharton survey of financial risk management by US non-financial firms. Financial Management, 27(4), 70-91. doi: $10.2307 / 3666414$

Brown, G. W., Crabb, P. R., \& Haushalter, D. G. (2006). Are firms successful at selective hedging? Journal of Business, 79(6), 2925-2949.

Carter, D., Rogers, D., \& Simkins, B. (2006). Does hedging affect firm value? Evidence from the US airline industry. Financial Management, 35(1), 53-86. doi: 10.1111/j.1755053X.2006.tb00131.x

Coutinho, J. R. R. S., Sheng, H. H., \& Lora, M. I. (2012). The use of Fx derivatives and the cost of capital: evidence of Brazilian companies. Emerging Markets Review, 13(4), 411-423. doi: 10.1016/j.ememar.2012.07.001

Froot, K. A., Scharfstein, D. S., \& Stein, J. C. (1993). Risk management: coordinating corporate investment and financing policies. The Journal of Finance, 48(5), 1629-1658. doi: 10.1111/j.1540-6261.1993.tb05123.x

Géczy, C. C., Minton, B. A., \& Schrand, C. M. (1997). Why firms use currency derivatives. Journal of Finance, 52(4), 1323-1354. doi: 10.1111/j.1540-6261.1997.tb01112.x

Géczy, C. C., Minton, B. A., \& Schrand, C. M. (2007). Taking a view: corporate speculation, governance and compensation. Journal of Finance, 62(5), 2405-2443. doi: 10.1111/j.15406261.2007.01279.x

Hentschel, L., \& Kothari, S. P. (2001). Are corporations reducing or taking risks with derivatives? Journal of Financial and Quantitative Analysis, 36(1), 93-118. doi: 10.2307/2676199 
Jin, Y., \& Jorion, P. (2006). Firm value and hedging: evidence from U.S. oil and gas producers. The Journal of Finance, 61(2), 893-919. doi: 10.1111/j.1540-6261.2006.00858.x

Nance, D. R., Smith, C. W., Jr., \& Smithson, C. W. (1993). On the determinants of corporate hedging. The Journal of Finance, 48(1), 267-284. doi: 10.1111/j.1540-6261.1993.tb04709.x

Novaes, W., \& Oliveira, F. N. (2005). Demanda de derivativos de câmbio no Brasil. Hedge ou especulação? [Working paper $\mathrm{n}^{\circ}$ 2005-14]. Economics Research Group IBMEC Business School, Rio de Janeiro, RJ, Brasil.

Novos instrumentos para controlar velhas práticas. (2009, novembro 19). Editorial. Valor Econômico, (2388), Ano 10, p. A-16.

Oliveira, R. F., Schiozer, R., \& Leão, S. (2012). Atuação de bancos estrangeiros no Brasil: mercados de crédito e derivativos de 2005 a 2011 [Trabalhos para Discussão n 298]. Banco Central do Brasil, Brasília, DF, Brasil.

Rossi, J. L., Jr. (2011). Hedge or speculation? Evidence of the use of derivatives by Brazilian firms during the financial crisis [Working paper $n^{\circ}$ 243/2011]. Instituto de Ensino e Pesquisa, São Paulo, SP, Brasil. Recuperado de http://en.insper.edu.br/sites/default/files/2011_wpe243.pdf

Rossi, J. L., Jr. (2012). Understanding Brazilian companies' foreign exchange exposure. Emerging Markets Review, 13(3), 352-365. doi: 10.1016/j.ememar.2012.03.007

Rossi, J. L., Jr., \& Laham, J. (2008). The impact of hedging on firm value: evidence from Brazil. Journal of International Finance and Economics, 8(1), 76-91.

Saito, R., \& Schiozer, R. F. (2007). Uso derivativos em empresas não-financeiras listadas em bolsa no Brasil. Revista de Administração, 42(1), 97-107.

Schiozer, R. F., \& Saito, R. (2009). The determinants of currency risk management in Latin American nonfinancial firms. Emerging Markets Finance and Trade, 45(1), 49-71. doi: 10.2753/REE1540-496X450104

Serafini, D. G., \& Sheng, H. H. (2011). O uso de derivativos da taxa de câmbio e o valor de mercado das empresas brasileiras listadas na Bovespa. Revista de Administração Contemporânea, 15(2), 283-303. Recuperado de http://www.scielo.br/pdf/rac/v15n2/v15n2a08.pdf. doi: $10.1590 / \mathrm{S} 1415-65552011000200008$

Smith, C. W., \& Stultz, R. M. (1985). The determinants of firm's hedging policies. Journal of Financial and Quantitative Analysis, 20(4), 391-405. doi: 10.2307/2330757

Stulz, R. M. (1984). Optimal hedging policies. The Journal of Financial and Quantitative Analysis, 19(2), 127-140. doi: 10.2307/2330894

Stulz, R. M. (1996). Rethinking risk management. Journal of Applied Corporate Finance, 9(3), 8-24. doi: 10.1111/j.1745-6622.1996.tb00295.x 